\title{
Moralidade fiscal e o papel das autoridades tributárias: economia comportamental e análise do caso brasileiro
}

\section{Felipe Cocenas Vazquez*, Gustavo de Oliveira Aggio}

\begin{abstract}
Resumo
O presente trabalho buscou demonstrar que existem, dentro da literatura econômica, métodos de análise que não partem dos pressupostos neoclássicos de agente econômico e, ainda assim, provem uma explicação para o problema da evasão fiscal. Foi feita uma revisão da literatura acerca da 'tax morale' (motivação intrínseca a pagar impostos), do cumprimento fiscal e de aspectos da economia comportamental que fossem pertinentes ao exame destes temas. Realizou-se também uma compilação de experimentos sociais empreendidos mundialmente que visaram elevar o nível de cumprimento fiscal e, por consequência, a 'tax morale'; buscou-se estabelecer uma relação entre estes experimentos e a literatura revisada. Por fim, é feita uma breve apresentação de experimentos que ocorreram no Brasil. Foi concluído que estes métodos de análise alternativos e suas aplicações podem contribuir positivamente com o cumprimento fiscal.
\end{abstract}

\section{Palavras-chave: moralidade fiscal, economia comportamental, tributação}

\section{Introdução}

O primeiro modelo formal de estudo sobre o problema da evasão fiscal, proposto por Allingham e Sandmo (1972), defendia, a partir dos pressupostos de plena racionalidade e informação, que o montante de evasão fiscal em uma sociedade seria negativamente correlacionado à probabilidade de detecção e o grau de punição dado ao indivíduo que incorresse no crime. A forma ideal para combater a evasão fiscal seria, dado esse resultado, aumentar a probabilidade através de maior rigor no tratamento dado aos contribuintes. Entretanto, os resultados esperados por estes modelos não correspondiam ao que se via na realidade, pelo que se encontrou a necessidade de novas abordagens. A partir da incorporação de aspectos psicológicos individuais, análises mais recentes têm apresentado resultados diferentes e proposto soluções alternativas. Este trabalho se propôs a realizar uma síntese da literatura que aborda o tema da evasão fiscal através destas análises e identificar de que forma sua utilização por parte das autoridades tributárias pode ser benéfica.

\section{Resultados e Discussão}

Os estudos realizados com o fim de incorporar aspectos psicológicos à análise da evasão fiscal buscavam, como objetivo principal, entender a maneira mais eficaz de se elevar o nível da tax morale - motivação intrínseca a pagar impostos - nos indivíduos de uma sociedade. A inserção destes aspectos psicológicos abriu espaço para que a corrente da economia comportamental entrasse no tema e inserisse suas principais ideias: a orientação através do uso das heurísticas, a aversão às perdas, o status quo bias e, principalmente, a utilização dos nudges, que nada mais são do que intervenções embutidas na apresentação de uma escolha aos indivíduos que visam alterar seu comportamento sem proibir ou restringir qualquer ação. $\mathrm{Em}$ diversos experimentos sociais, o uso de cartas com design comportamental demonstrou relativa efetividade em elevar o cumprimento fiscal.

Entretanto, através dos experimentos com as mesmas cartas foi observado que esta não seria a única forma de minar a evasão fiscal: o governo também pode estimular comportamentos desejados nos indivíduos através de outros mecanismos baseados em normas sociais e na percepção de legitimidade e justiça do sistema tributário. No caso do primeiro, as normas sociais funcionam como uma espécie de heurística social, através da qual os indivíduos de uma sociedade guiam suas ações na falta de informações precisas sobre as consequências de atos individuais. Já no caso do segundo, constatou-se que a criação de uma comunidade onde os cidadãos têm valores internos que levam ao respeito às leis depende de que elas sejam baseadas no consentimento voluntário e, principalmente, na cooperação, imperando a percepção de um tratamento justo e estabelecendo uma relação de confiança entre governo e sociedade. Neste último caso, deve-se ressaltar que o nível de participação direta nas decisões democráticas pode afetar positivamente o cumprimento fiscal.

Por fim, a pesquisa encontrou poucos experimentos comportamentalistas expressivos no Brasil. O primeiro, realizado no Rio de Janeiro através de cartas elaboradas a partir de design comportamental, apontou que o sentimento de cooperação entre os cidadãos da cidade e o governo é baixo, algo que pode ser explicado pelo decrescimento em sua qualidade de vida nos últimos anos. No Estado de São Paulo, tivemos o caso de sucesso do Nota Fiscal Paulista, que apesar de estar mais relacionado a um incentivo fiscal do que a um experimento comportamentalista, apresentou resultados extremamente positivos.

\section{Conclusões}

Abordagens teóricas que incorporam aspectos da economia comportamental e da psicologia têm mostrado melhor poder de explicação para o problema da evasão fiscal se comparadas ao modelo proposto por Allingham e Sandmo (1972). A elevação da tax morale e do cumprimento fiscal pode ser alcançada através de políticas públicas que considerem a utilização de nudges fiscais, apelo às normas sociais e ao sentimento de legitimidade e justiça por parte dos contribuintes.

\section{Agradecimentos}

Gostaria de agradecer ao CNPq pelo financiamento da bolsa de Iniciação Científica.

ALLINGHAM, M., SANDMO, A., Income tax evasion: a theoretical analysis Journal of Public Economics, v.1, p. 323-338, 1972.

LUTTMER, E., SINGHAL, M. "Tax morale." Journal of Economic Perspectives, v. 28, n. 4, p. 149-68, 2014 